\title{
Genetics Resources on the Web (GROW)
}

\author{
Alan E. Guttmacher, $M D$, and Francis S. Collins, MD, PhD
}

In medicine, this may be the Age of Human Genetics; in technology, the Age of the Internet. It is not surprising, then, that the intersection of these two, "human genetics on the Web," is a focus of increasing interest. Until recently, however, those sharing this interest had no effective means to communicate with each other, consider issues of common concern, or work collaboratively.

Recent rapid proliferation of Web sites that provide information for health professionals and the general public about human genetics, especially human medical genetics, offers the promise that comes from wide and easy availability of multiple information resources. However, this proliferation also raises the perils that such resources may be of inconsistent quality or that their large number may confuse rather than encourage users. Unnecessarily duplicative efforts threaten to waste the limited staff and financial resources of organizations mounting these Web sites and to overburden the small pool of creators of expert information about human genetics.

\section{THE ORIGIN OF GROW}

In an effort to further the promise and to minimize the perils of this nascent field, in the summer of 1999 the National Human Genome Research Institute, with financial collaboration from the Office of Rare Diseases at the National Institutes of Health (NIH), convened a meeting of over two dozen organizations (see Table 1) that have a particular interest in the use of the Web to inform both health professionals and the public about human genetics. The hope was that this forum would further communication and collaboration among these organizations and stimulate joint consideration of issues of common concern. That all but one of the invited organizations were able, on short notice, to attend a meeting in the middle of August was testimony to their level of enthusiasm.

This day-long inaugural meeting, held at the NIH on August 17, 1999, included short presentations from attendees regarding their current or planned Web sites. Most of the meeting was spent discussing issues of common concern. This discussion began by focusing on common obstacles in providing quality human genetics information on the Web and considering whether, despite robust Web resources in genetics, unmet needs ("gaps") exist.

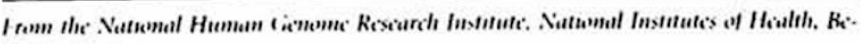
thesla, Mlariand.

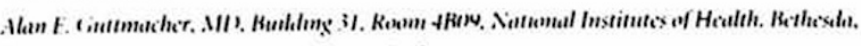

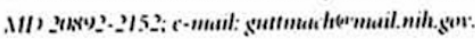

Among the unmet needs and common obstacles discussed were barriers to access to sites, including financial and socioeconomic factors that limit potential users' access and passwords that limit access; lack of user feedback about their needs and about their views of the sites; lack of formal usability testing of sites; lack of user-specific gateways; difficulty in making sites financially viable; technical issues, such as printing frames; difficulty in making sites friendly to the search engines and Web directories that potential users utilize; and lack of a search engine that looks simultaneously across multiple quality human genetics Web sites.

The discussion then centered on needs assessment. Several organizations shared their plans in this area. It was noted that different user audiences have different needs and since the organizations present seek to address multiple audiences, they confront multiple sets of needs. However, it was also noted that, particularly in dealing with genetics aspects of common disorders, certain issues recur frequently, e.g., understanding what is predisposition and how to deal with presymptomatic risk. There was general agreement that assessment is needed both of users' needs and of sites. Aspects of sites that should be assessed include content, technology, effectiveness, recency of updating, access, and fairness.

The group briefly discussed whether duplications exist among Web sites and, if so, whether this is a problem. It was quickly agreed that duplications were a significantly lesser problem than were "gaps." It was acknowledged, however, that duplicative efforts pose a significant burden for the limited pool of available creators of quality Web content in human genetics.

Discussion then focused on means to increase communication and collaboration among the organizations present. This led, at the meeting's close, to agreement on several actions. The success of this initial meeting led attendees to establish an umbrella organization, Genetics Resources on the Web (GROW), that would foster communication and collaboration. It was determined that GROW's next meeting should occur over two days in the early spring of 2000 at the NIH. A listserv was established to enable individuals participating in the meeting to communicate efficiently with each other. A Search Working Group was established and charged with considering how to make sites appear more prominently on the searches of external engines, Web directories, and portals and with considering how to create a capability for searching across multiple sites simultaneously. An Assessment Working Group was established and charged with considering development of a standardized instrument for evaluating sites; recommending what, if any, minimal standards should be established for sites; and 
Table 1

Genetics Resources on the Web: Participating Organizations

\begin{tabular}{|c|c|}
\hline American College of Medical Genetics ${ }^{1,2}$ & www.faseb.org/genetics/acmg \\
\hline American Society for Human Genetics ${ }^{1,2}$ & www. faseb.org/genetics/ashg/ashg'menu.htm \\
\hline Celera Genomics $^{2}$ & www.celera.com \\
\hline Centers for Disease Control and Prevention 1.2 & www.cdc.gov/genetics/ \\
\hline Children's Hsopital of Cincinnati ${ }^{2}$ & www.gpnf.org \\
\hline Coalition of State Genetics Coordinators ${ }^{2}$ & None \\
\hline Department of Energy ${ }^{1.2}$ & www.ornl.gov/hgmis/resource/assist.html \\
\hline Foundation for Genetic Education and Counseling ${ }^{1,2}$ & www fgec.org \\
\hline Foundation for Genetic Medicine, Incorporated ${ }^{\prime}$ & www.GeneticMedicine.org/ \\
\hline GeneClinics $^{1.2}$ & www.geneclinics.org \\
\hline The Gene Media Forum ${ }^{1.2}$ & None \\
\hline GeneSage $^{2}$ & www'genesage.com \\
\hline Genetic Alliance ${ }^{1,2}$ & wnww.geneticalliance.org \\
\hline Genetic Awareness Coalition 1.2 & None \\
\hline Genetic Health ${ }^{2}$ & www.genetichealth.com \\
\hline Genetics in Medicine ${ }^{2}$ & www/lww.com/GIM \\
\hline GeneTests $^{1.2}$ & www:genetests.org \\
\hline Health Resources and Services Administration 1.2 & wivw.mchb.hrsa.gov/genetics.htm \\
\hline Infogenetics ${ }^{2}$ & wu'w.infogenetics.org \\
\hline International Society of Nurses in Genetics 1.2 & mursing.creighton.edu/isong \\
\hline Kansas University Medical Center ${ }^{1.2}$ & www.kumcedu/gec/geneinfo.html \\
\hline March of Dimes ${ }^{1.2}$ & wuwv.modimes.org \\
\hline National Cancer Institute ${ }^{1,2}$ & cancernet.nci.nih.gov \\
\hline National Center for Biotechnology lnformation ${ }^{1.2}$ & www.ncbi.nlm.nih.gov and www.ncbi.nlm.nih.gov/disease \\
\hline National Coalition for Health Professional Education in Genetics ${ }^{1.2}$ & www.nchpeg.org \\
\hline National Human Genome Research Institute ${ }^{1.2}$ & www.nhgri.nih.gov \\
\hline National Institutes of Health, Office of the Director ${ }^{1,2}$ & www:nih.gov \\
\hline National Institutes of Health, Office of Extramural Research² & ww'w.nih.gov/sigs/bioethics \\
\hline National Organization for Rare Disorders ${ }^{1.2}$ & "ww. rarediseases.org/ \\
\hline National Society of Genetic Counselors 1,2 & www.nggc.org/ \\
\hline Office of Rare Diseases ${ }^{1,2}$ & rarediseases.info.nih.gov/ord/ \\
\hline Online Mendelian Inheritance in Man' & www3.ncbi.nlm.nih.gov/Omim \\
\hline Orchid BioSciences, Inc. ${ }^{2}$ & www.geneshield.com \\
\hline Pew Charitable Trusts' & menv. pewtrusts.com \\
\hline Pharmaceutical Research \& Manufacturers of America ${ }^{1,2}$ & w'ww.phrma.org/genomics/ \\
\hline Robert Wood Johnson Foundation' & www.rwif.org/main.html \\
\hline State of Hawaii Genetics Program² & None \\
\hline U.S. Pharmacopeia ${ }^{1.2}$ & mww.usp.org \\
\hline
\end{tabular}

'Attended GROW I, August 1999.

${ }^{2}$ Attended GROW II, March 2000 
discussing whether sites should evaluate each other and/or have external experts evaluate them.

\section{CONTINUING PROJECTS}

Both working groups were active during the interval between GROW's first and second meetings. Along with developing strategies to enable GROW participating organizations to be more prominent on external search engines, the Search Working Group developed a "beta version" of a GROW-based search engine that would search simultaneously across the several dozen sites that are GROW participants (to test a very preliminary version, visit $h t t p: / / s e a r c h$.info.nih.gov/grow/). It is hoped that an improved version of this search engine, capable of serving as a "one-stop" point of entry into several dozen quality sites with information about human genetics, will be freely available to the public later in 2000 .

The Assessment Working Group focused on developing standards and quality assurance mechanisms for sites that wish to participate in GROW. It sought to help participating organizations improve their Web sites and to assure that all sites incorporated into the GROW search engine meet standards regarding not only quality of information presented, but also privacy, declaration of financial interests, etc.

\section{SECOND MEETING}

GROW held its second meeting at the NIH on March 27-28, 2000; more than 30 organizations attended (see Table 1). As with the first meeting, organizations briefly described their current and planned Web sites.

The Assessment Working Group presented its report, which led to general discussion of the desirability of maintaining "balance" in content and views expressed on sites. Some felt that if a site clearly states its sources of support, biases, etc., then balance is not necessary; others disagreed with this view. Also discussed was the size at which a site, to be effective, requires an internal search engine. The need for the working group to address issues of access both at a technical level (as they affect, for instance, use of the Web by those with disabilities) and at a broader socioeconomic level was identified. The working group was also asked to comment more extensively and explicitly about issues of confidentiality and privacy and issues related to commercial uses of health-related sites. Concern was also raised that GROW still needs to identify gaps in what is available on the Web about human genetics; the working group agreed, with input from other GROW participants, to do so.

The Search Working Group presented its report. Subsequent discussion centered on possible models for a "GROW Search Engine." Of these, a "centralized search engine" (an engine that simultaneously searches all incorporated sites) and a "rolodex" model (in which member sites would contribute their information to form a topic-based directory) received the most support. The working group agreed to explore these models, including determining approximate costs to establish and maintain each.

The meeting's second day began with brief discussion of issues of common concern, the first of which was optimal use of expert content providers. One problem in this area is finding economic support and other incentives for content providers and for Web editing. Possible responses included communication among GROW members about models of support, standardizing citation for Web-based publications, and encouraging academic recognition for Web-based publishing. Other problems cited included attracting experts who are not yet comfortable with the Web and Web-based publishing and verifying that an "expert" has true expertise. Another problem was duplication and wasted effort of expert content providers; it was felt that GROW might respond by serving as a clearinghouse between content providers and Web sites and by using its search engine to identify duplication. For another problem, finding reviewers for Web sites, it was suggested that GROW might help by encouraging communication among its members and by serving as a clearinghouse between sites and potential reviewers.

Also discussed were concerns regarding proprietary issues and conflict of interest. It was suggested that GROW might adopt a code(s) of conduct, such as that of the Health on the Net Foundation (HON) code (http://www.hon.ch/HONcode/).

Another issue of concern was quality assurance, in terms of what works from the user's perspective. One suggestion for dealing with this was to obtain feedback from site users, as Web-based retailers do.

The group identified several problems regarding effective Web site links, including acquiring quality links, vetting links, determining how far down the "chain of links" vetting is required, annotating links, and pruning links. The group explored ways that participating organizations might help each other become more efficient and effective with these functions. The suggestion with the most support was to use the GROW listserv to facilitate communication about these functions so that organizations could utilize others' trusted information regarding links, rather than duplicating the significant effort necessary to obtain that information.

Based on a preliminary draft of organizational guidelines for GROW circulated prior to the meeting, the group discussed a number of matters regarding GROW's function and structure. Among issues discussed was GROW's mission, specifically whether GROW should restrict membership to sites interested in human medical genetics as opposed to human genetics in general. Consensus was reached that GROW should offer membership to sites interested in human genetics, while maintaining its special focus on medical and public health genetics.

Another issue regarding membership criteria was whether adherence to the HON code and/or other similar codes, or even certification by HON and/or a similar body, should be required of all sites that desire to become members and/or be included on the GROW search engine. How member sites should handle issues concerning real or perceived conflict of 
interest was also debated. The Assessment Working Group agreed to explore further whether the HON or other similar codes are appropriate for GROW and whether GROW requires supplementary criteria, particularly in the areas of privacy/ confidentiality and conflict of interest. Another question about membership criteria was what technical requirements would inclusion on the GROW search engine require. The Search Working Group agreed to explore this question.

The issue of peer review of GROW member sites was also raised, specifically whether passing peer review should be a formal prerequisite for GROW membership rather than peer review being an informal, voluntary process. It was agreed that GROW should encourage members to offer informal feedback to each other but should require neither the request nor provision of such feedback. Such feedback would be more "technical assistance" than "peer review."

The group considered various models for funding GROW activities, especially maintenance of the search engine. A Funding Working Group was formed to explore this further.
GROW's operating structure was discussed. Consensus was that, since function dictates structure and GROW's functions were still being defined, decisions about structure should be tabled.

At the meeting's close, it was agreed that GROW's next meeting would occur over two days in the fall of 2000 at the $\mathrm{NIH}$. The dates for this meeting were later set as November 30-December 1, 2000.

\section{SUMMARY}

Genetics Resources on the Web (GROW) seeks to provide an effective forum that encourages communication and collaboration among individuals and organizations interested in Web-based information in human genetics. Its mission is to optimize Web-based provision of high-quality information about human genetics, especially those aspects of human genetics dealing with health, to health professionals and the public. 